\title{
WhatsApp Acceptance: A Comparison Between Individualistic and Collectivistic Cultures
}

\author{
Serri FAISAL and Ghassan AL-QAIMARI
}

Emirates College of Technology. UAE

Correspondence should be addressed to: Serri FAISAL; Serri.Faisal@ect.ac.ae

Received date: 20 November 2019; Accepted date: 7 May 2020; published date: 16 June 2020

Copyright (C) 2020. Serri FAISAL and Ghassan AL-QAIMARI. Distributed under Creative Commons Attribution 4.0 International CC-BY 4.0

\begin{abstract}
Social media applications led by WhatsApp have exhibited a great adoption rate in individualistic and collectivistic societies. To study the factors which influence the adoption of software applications across cultures, the application design was studied by researchers in both individualistic and collectivistic societies. Most of such studies concentrated on the application design from the developer's point of view. Differently, this research study empirically explores the factors that influence the adoption of smartphone apps, such as WhatsApp, from the user's perspective. Therefore, the focus in this paper is on the moderating effect of Hofstede's crosscultures dimension, individualism vs. collectivism (IDV), and the interconnection between the persuasive system design (PSD) and acceptance. A total of 488 responses were collected from societies which span on the spectrum of IDV to include two individualistic societies, Netherlands and Germany, and two collectivistic societies, Malaysia and the Kingdom of Saudi Arabia. The overall results indicate that persuasive design principles are relevant to cultures across the globe. Moreover, individualism has a negative influence on the correlation between the persuasive system design principles and acceptance. Consequently, the findings suggest that in collectivistic societies, PSD principles have a stronger influence on the acceptance of smartphone apps. Thus, smartphone apps that are targeting the global community would highly benefit from the implementation of PSD principles which can lead to a higher adoption.
\end{abstract}

Keywords: Application adoption, social media, cross-culture, Collectivism, Individualism.

Cite this Article as: Serri FAISAL and Ghassan AL-QAIMARI (2020), "WhatsApp Acceptance: A Comparison Between Individualistic and Collectivistic Cultures", Journal of Internet Social Networking \& Virtual Communities, Vol. 2020 (2020), Article ID 914643, DOI: 10.5171/2020.914643 


\section{Introduction}

Cultural factors in software applications design was studied by researchers across both individualistic and collectivistic societies. To provide systematic guidelines for designing persuasive systems, Fogg (2002) and Oinas-Kukkonen \& Harjumaa (2009) developed instruments for the systems' designers; however, empirical studies that tested the design theory in different cultures from the user's perspective are still lacking. Therefore, this study investigates the moderating effect of "individualism", as a cross-cultural dimension, on the relationship between the apps' persuasive design principles and the user's acceptance.

In order to progress further in the research related to exploring cultural effects, it must be classified and empirically described (Gong et al., 2007). Differences among cultures that can be measured relative to other cultures are defined by cultural dimensions, which are obtained by empirical studies involving statistical analysis of large-scale questionnaires (Hall et al., 2004). The most researched theories of cultural dimensions were developed by Hall (1973), Geert Hofstede (1983), and Trompenaars and Hampden-Turner (1998).

Hofstede's model has been the most cited and most accepted framework in crosscultural studies in the field of HumanComputer Interaction (HCI) (Hofstede et al., 2010; Kamppuri et al., 2006; Steenkamp \& Geyskens, 2006). Hofstede defines behavioral models as "mental programs" and he argues that these mental programs shape values, beliefs and behaviors of individuals. The data for cultural dimensions were collected in the 1970s in IBM. As a result of his analysis, more than 70 countries were classified along each dimension in a scale from 0 to 100 . Hofstede later added a sixth dimension called "indulgence" (Hofstede, 2010).

\section{Design Theories}

\section{Persuasive Design for Smartphone Applications}

One of the most comprehensive application design models was the Persuasive System Design Model (PSD), which was developed by Oinas-Kukkonen \& Harjumaa (2009) to aid software designers create persuasive applications for a wider acceptance and a continued use. The PSD model offers 28 persuasive design principles intended to support the development of persuasive systems. Designers can select some or all the principles during the design phase. The model provides app designers with a measure of freedom to express their creativity. The PSD model's principles are grouped into four distinct categories: primary task support, dialog support, system credibility and social support (OinasKukkonen \& Harjumaa, 2009).

\section{Hofstede's Cross-Cultural Model}

Culture is an abstract and a complex construct that shapes and affects human behavior. It is not genetically inherited, but a learned phenomenon that is acquired through socialization (Hofstede, 1983b). Different aspects can define culture, but for the purpose of this research, a concept that was introduced by Hofstede (2011) was chosen. The author defines culture as "the collective programming of the mind that distinguishes the members of one category of people from those of another" (Hofstede, 2011). Consequently, people create a "subjective reality" of customs, beliefs, values and logic that reflects their own culture (Gong et al., 2007). Each country has a different set of cultural values, yet there are also slight differences in distinct regions in larger countries and even in different social groups (Gupta \& Jain, 2015).

The model originally consisted of five dimensions to measure the characteristics of a culture. These dimensions are Power 
Distance (PDI), Collectivism versus Individualism (IDV), Femininity versus Masculinity (MAS), Uncertainty Avoidance (UAI) and Long-Term versus Short-Term Orientation (LTO) (Hofstede \& Hofstede, 2010). A sixth dimension, Indulgence versus Restraint (IND), was later added in 2010 by Hofstede (Hofstede, 2011).

Individualistic countries pertain to those where relationships among individuals are loose. In high individualistic countries (e.g., the United States and European countries), people are expected to look after themselves and their immediate families. People in such societies tend to speak their minds as a sign of honesty. Moreover, they are likely to believe that performing a task prevails over relationships. On the contrary, people in collectivist countries (e.g., Malaysia, South Korea and the Arab World) are integrated into powerful in-groups' bonds, characterized by unquestioning loyalty (Hofstede, 1993b). Unlike those in individualistic countries, people in collectivist countries tend to avoid direct confrontations and work while maintaining harmony with others.

The PDI dimension refers to the degree to which individuals within a country expect and accept the unequal distribution of power or wealth (Hofstede, 1993b). The cultural dimension UAI is defined by Hofstede (2005) as "the extent to which the members of a culture feel threatened by uncertain and unknown situations". This dimension addresses the degree to which an individual in a country can tolerate ambiguity or uncertain circumstances. (Hofstede \& Hofstede, 2005). Masculinity is an extent to which the dominant values of individuals are "masculine." Hofstede specified that people with such values tend to be assertive and competitive. (Hofstede \& Hofstede, 2005). The fifth cultural dimension, Long-term versus Short-term Orientation pertains to whether cultures show a future-oriented perspective or a short-term one.

\section{Cultural effects on the acceptance of smartphone applications}

One of the most popular and most used smartphone applications is the instant messaging (IM) feature. Instant messaging is an online chat app that is attractive to users because it is more spontaneous and convenient than traditional Short Messaging Service (SMS), email or phone call (Zhou, 2005). As of 2019, the most popular mobile messaging app worldwide is WhatsApp Messenger with 1.6 billion users worldwide (Statista, 2019). Li et al. (2011) investigated the factors which influence communication, while over such messaging applications, they found that cultural values and norms have a great influence on communication and that the cultural dimension of individualism vs. collectivism do matter in the instant messaging practice (Li et al., 2011). Examples of the way Chinese and Dutch use instant messages confirms this statement (Li, 2016). Chinese users showed more preferences towards group chat options, implicit communication and easier acceptance of different features on apps. Dutch people have more explicit interactions and less interest in other people's privacy. However, the most interesting result is the fact that the investigation of cultural dimensions leads to the proof of cross-cultural adoption of Chinese people living in the Netherlands, who have similar characteristics to both Chinese in China and Dutch in the Netherlands. When people are bi-cultural or multicultural, they don't fit into predefined categories, which complicates the interpretation of results on cultural dimensions (Biljon \& Kotzé, 2008).

The design for user interface of mobile data services is influenced by different cultural factors (Choi et al., 2005). Attributes which influence the adoption include fonts, colors, minimal keystrokes, icon recognition (Kim \& Lee, 2005) and menu style to users from different cultures and their preferences that are defined in Hofstede's dimensions. 
Sociodemographics represents the strongest indication for predicting the use of smartphone applications (Kim et al., 2015). Individual characteristics of users also influence the way people use apps. People with more wealth and better education tend to use smartphones more (Gong et al., 2007; Kim et al., 2015).

\section{Context of the Case: WhatsApp Messenger}

This study investigates the moderating effect of the individualism cross-cultural dimension on the acceptance of apps, which was designed according to PSD guidelines. WhatsApp is used as a case study to identify why users from diverse cultural backgrounds have adopted this smartphone application with the intention of continual utilization. PSD principles were implemented in WhatsApp design which makes it an ideal candidate for this research. This app has continually gained increasing popularity among people from diverse cultures, spanning over all age groups and both genders (Kasali et al., 2017).

Since the advent of widespread Smartphone adoption, researchers have sought to develop the optimal application design that corresponds to the needs of potential users in different cultures all over the world. Popular apps and games appear to succeed regardless of the cultural differences. Examples include WhatsApp, Facebook, YouTube and Twitter (Sawyer, 2011), and gaming software such as Half Life, The Sims and Civilization (Hammer \& Davidson, 2017).

WhatsApp works by using the Internet as an alternative to short messaging service (SMS), free at the point of use where the user has access to the Internet. WhatsApp is an effective messaging platform, providing exchange of texts and audio messaging, voice calls, photos, videos, documents, PDF files and user location data. As a micro SNS, it allows users to create their own digital profile, which includes a picture, a nickname and a status (Sánchez-Moya \& Cruz-Moya,
2015). A recent study on WhatsApp adoption among young people has revealed that undergraduates mostly communicate via text messages (98.10\%), photo messages (94.94\%) and exchanging information (62.03\%) (Ahad \& LIM, 2014). The global uptake of WhatsApp is considerable: By the third quarter of 2017, 73\% of Saudi Arabia's population were using WhatsApp, followed by Malaysia (68\%), Germany (65\%), Brazil and Mexico (56\%), Turkey (50\%) and South Africa (49\%) in 2017 (Statista 2018). When compared with similar apps like Viber and Telegram, WhatsApp was also the most popular messenger app in 2016 (Sutikno et al., 2016).

\section{Persuasive System Design Influence on Acceptance}

Earlier findings indicate an influence of the persuasive system design principles on acceptance (Faisal et al., 2019). These results were evident despite countries' culture orientation association. The overall model confirms the impact of primary task support and dialog support on acceptance. Furthermore, the overall model did not show a significant impact of social support on acceptance as it was supported only in the K.S.A. However, system credibility proved to be insignificant in all the countries included in this study. Application designs which appeal to users' aspirations and exigencies can increase the adoption of an application. Although cross-cultural characteristics pertain to acceptance (Hofstede \& Hofstede, 2010), PSD principles indicated a significant role in app acceptance. These findings challenge the proposals made by researchers regarding the role of cross-cultural characteristics in application acceptance. Therefore, it is necessary to investigate the role of cross-cultural dimensions in shaping the effect of PSD principles on acceptance. This part of the paper investigates the individualism vs. collectivism cross-cultural dimension. 


\section{Research Hypotheses}

Jennifer Aaker and Durairaj Maheswaran (1997) used dual process theories of persuasion to develop experiments examining culturally driven persuasion differences (Aaker \& Maheswaran, 1997). Their investigation focused on individualist and collectivist responses to low elaboration routes of persuasion-wherein people are, for whatever reason, unable to make considered decisions-and high elaboration routes of persuasion-wherein people are motivated to make decisions thoughtfully. The study showed that collectivists place more emphasis on consensus when under conditions of high elaboration. The findings may indicate that this cross-cultural dimension influences the relationship between the Persuasive Design System and a Smartphone users' acceptance. Hence, the following hypothesis is proposed:

HYPOTHESIS: There is a moderated effect of individualism vs. collectivism (IDV) crosscultural dimension on the relationship between Persuasive System Design (PSD) and the Smartphone app user's acceptance.

The dependent variable is Smartphone app User's Acceptance (SUA), which is the tendency of a Smartphone user to download and use an app. While the independent variable is the PSD which represents the PSD's four categories: Dialog Support (DS), Primary Task Support (PT), Social Support (SS) and System Credibility (SC). Finally, the moderating variable is the individualism vs. collectivism (IDV) cross-cultural dimensions.

\section{Data Collection and Analysis}

A two-step sampling method of data collection was used. The sampling error was adjusted by evaluating a probability sampling and a well-defined target population (Turner, 2003). The sample population was designed in order to achieve maximum responses, and from those who adopt Smartphones (Parejo et al., 2013). Respondents were selected randomly from the online general population, via invites, and educational institutions in Malaysia (96 participants), the Netherlands (167 participants), Germany (125 participants) and the Kingdom of Saudi Arabia (100 participants). The selection of those countries is due to the fact that they have different dimension scores according to Hofstede's Value Survey Module (VSM), and thus they represent a varying culture spectrum.

The study was a quantitative one and the main data collection instrument was a specially designed multiple-choice questionnaire. WhatsApp application was the focus of this analysis where data were collected from WhatsApp users only. The questionnaire was analyzed prior to a large parent study to test the validity and reliability of the questionnaire. A pilot study enabled the researcher to validate that all the variables are properly adopted.

The research hypotheses were tested using regression analysis. The analysis method employed SPSS software using PROCESS macros that operates the inferring process and generates output much more efficiently and does not require great effort and programming skills to employ. PROCESS is a relatively new tool, which is an add-on for SPSS and is employed for statistical mediation, moderation and conditional process analysis.

The collected data indicates that only $34.3 \%$ of the respondents agreed that individuals should sacrifice self-interest for the group, reflecting a tendency of high individualism (IDV1). Half of the respondents in the sample $(50.0 \%)$ agreed that individuals should stick with the group even through difficulties (IDV2). Overall, $43.0 \%$ of the respondents agreed that group welfare is more important than individual rewards (IDV3). Also, 46.9\% of the respondents agreed that group success is more important than individual success (IDV4). As few as $38.2 \%$ of the respondents agreed that individuals should pursue their goals only after considering the welfare of

Serri FAISAL and Ghassan AL-QAIMARI (2020), Journal of Internet Social Networking \& Virtual Communities, DOI: 10.5171/2020.914643 
the group (IC5). Also, 38.2\% of the respondents agreed that group loyalty should be encouraged even if individual goals suffer (IDV6). Overall, the majority of the respondents in the sample have a tendency of relatively high individualism.

\section{Results}

In accordance with the research objectives, this section presents the results for the main effects of PSD on user acceptance and the moderation effects of each cross-cultural dimension with data pooled from all countries. Describing the boundary conditions of a mechanism allows a greater understanding of an effect, more than just understanding the mechanism itself. The majority of studies in communication science have only examined a single moderator as a simple mechanism of conditional processes. However, there are numerous other models that, while more complicated, allow researchers to unveil more nuanced relationships between variables. For example, Hayes et al. (2017) discuss the indirect effects of moderating variables
(Hayes et al., 2017). In this section, the Moderator Analysis model included three variables: (1) the dependent variable Y which represents the Smartphone app user acceptance (SUA), the independent variable $\mathrm{X}$, which represents the composite variable Persuasive System Design (PSD), and the moderator variable $\mathrm{M}$ represents the crosscultural dimensions (CCD), which is individualism vs. collectivism.

The overall model is statistically significant and the variables explain together $45.5 \%$ of the variance in SUA: F $(3,484)=135.88, p<$ $.001, \mathrm{R} 2=.45$. With respect to the individualism vs. collectivism dimension (IDV), it is found that the main effect on SUA is not statistically significant: $\mathrm{b}=.21, \mathrm{t}$ (484) $=1.82, \mathrm{p}>.05$. However, the Persuasive System Design (PSD) variable is significant, having a positive effect on SUA $(b=.86, t$ $(484)=13.97, p<.001)$. Thus, for every oneunit increase in PSD, there is a .86 unit increase in SUA. In addition, the interaction $(P S D \times I D V)$ is significant, indicating that the moderating variable IDV has a negative effect on the relationship between PSD and SUA: $b$ $=-.99, \mathrm{t}(484)=-7.16, \mathrm{p}<.001$.

Table 1: Model for all countries

\begin{tabular}{|l|l|l|l|l|l|l|}
\hline & Coeff (b) & SE & $\mathbf{t}$ & $\mathbf{p}$ & LLCI & ULCI \\
\hline constant & $4.1747(\mathrm{a})$ & .0421 & 99.0544 & .0000 & 4.0919 & 4.2575 \\
\hline IDV & .2145 & .1181 & 1.8160 & .0700 & -.0176 & .4465 \\
\hline PSD & .8605 & .0616 & 13.9684 & .0000 & .7395 & .9816 \\
\hline int_1 & -.9917 & .1385 & -7.1582 & .0000 & -1.2639 & -.7195 \\
\hline
\end{tabular}

The value of R Square Change (0.069) shows an increase in accounted for variance due to the addition of the interaction variable (PSD $\times$ IDV). This change added an additional 6.9\% of accounted for variance and was statistically significant $(\mathrm{F}(1,484)=51.24, \mathrm{p}$ $<$.001). It can be concluded that individualism vs. collectivism (IDV) moderates the relationship between Persuasive System Design and SUA. 


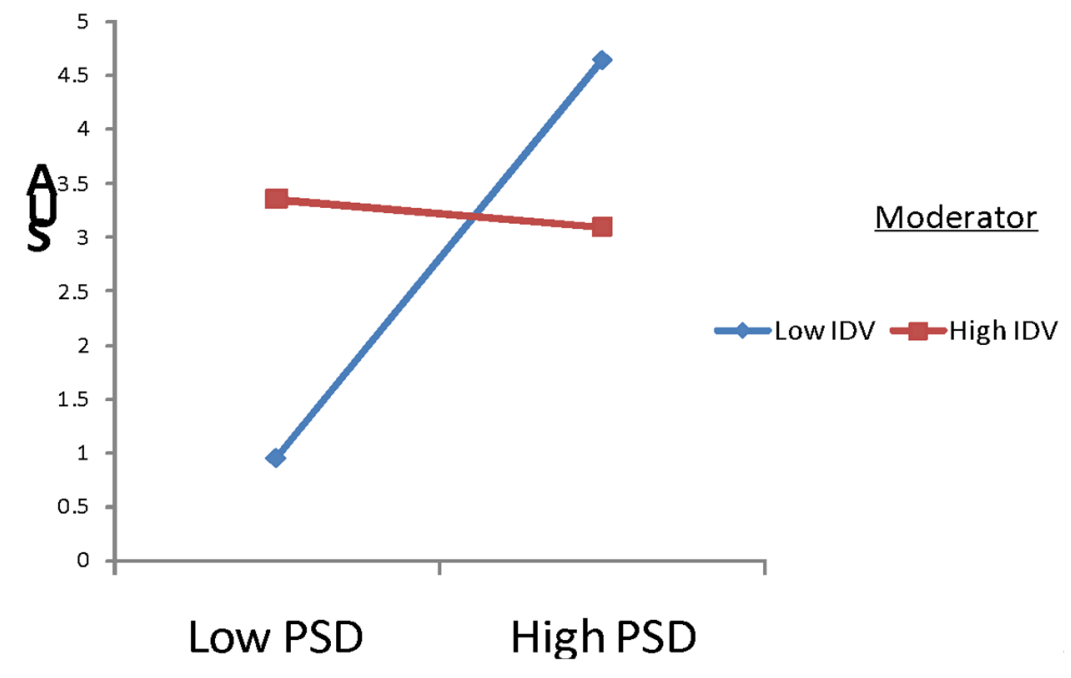

Figure 1: Scatterplot = PSD with SUA by IDV (M)

Specifically, as seen in Figure 1, IDV moderates the relationship between PSD and SUA, such that the positive relationship between PSD and SUA becomes weaker as individualism becomes stronger.

INFERENCE: There is a moderated effect of individualism vs. collectivism (IDV) on the relationship between PSD and users' acceptance for smartphones (SUA) for all the respondents. Consequently, the support for the above Hypothesis was found.

\section{Discussion}

The moderating effects of individualism vs. collectivism cross-cultural dimension were tested in the context of a globally popular smartphone app, WhatsApp, with participants from four countries (Malaysia, the Netherlands, Germany and the Kingdom of Saudi Arabia). Results from the regression analyses revealed that this has a moderating effect on the relationship between persuasive design and app user acceptance; thus, this relationship is positively impacted in collectivist societies, which was not initially anticipated. Furthermore, the higher individualism weakens the relationship between persuasive designs and user acceptance.

Therefore, more persuasive designs lead to higher user acceptance of the app in collectivist countries such as Malaysia. The level of individuality a person has, in other words, how influenced they are by the collective, is an important factor. This is in line with previous studies which show that cultural values and norms have a great influence on communication, and that the cultural dimension of individualism vs. collectivism do matter in the instant messaging practice (Li et al., 2011). A characteristic of high individualism is that they are willing to explore and be apart from the crowd (Hofstede, 1991). This means that they could accept the app more easily as it tends to underline their differences from others. Indeed, the acceptance may be a part of their efforts to differentiate themselves from others; thus, a more persuasive app design is not necessarily more effective in individualist countries such as the Netherlands. Therefore, culture and societal 
norms may still influence people's acceptance and perception of apps and other technologies.

\section{Implication to Practice}

When considering the PSD principles within the design, lower development cost and faster delivery to the global market could be achieved as it is the case with WhatsApp, Facebook, Google.com and most gaming applications which are accepted by people from all cultures. Those applications have the same interface, same design and same features for all cultures; however, PSD principles are well established within their designs. PSD now means that local features should be seamlessly integrated into a product or a technology. Nevertheless, app developers should remain culturally sensitive, while positioning their apps for a global audience because users are increasingly thinking in global terms and this is a trend that is only going to become more pronounced.

\section{References}

1. Aaker, J. and Maheswaran, D. (1997), 'The effect of cultural orientation on persuasion,' The Journal of Consumer Research 24, 3 (December 1997), 315 $-328$.

2. Ahad, A. D. and Lim, S. M. A. (2014), 'Convenience or Nuisance? The 'WhatsApp' Dilemma,' Procedia - Social and Behavioral Sciences, 155, 189-196. doe:

http://dx.doi.org/10.1016/j.sbspro.20 14.10.278.

3. Biljon, J. Van and Kotzé, P. (2008),'Cultural Factors in a Mobile Phone Adoption and Usage Model,' Journal of Universal Computer Science, 14(16), 2650-2679. https://doi.org/10.3217/jucs-014-162650.
4. Choi, B., Lee, I., Kim, J. and Jeon, Y. (2005), 'A qualitative cross-national study of cultural influences on mobile data service design.' Paper presented at the Proceedings of the SIGCHI Conference on Human Factors in Computing Systems, Portland, Oregon, U.S.A.

5. Faisal, S., Nor Aziati, A. H. and Abdullah, N. H. (2019), 'Persuasive system design for global acceptance of smartphone apps,' Procedia Computer Science (Vol. 152, pp. 44-50). Elsevier B.V.

https://doi.org/10.1016/j.procs.2019. 05.025 .

6. Fogg, B. J. (2002),'Persuasive Technology: Using Computers to Change What We Think and Do,' Morgan Kaufmann.

7. Gong, W., Li, Z. G. and Stump, R. L. (2007), 'Global internet use and access: cultural considerations,' Asia Pacific Journal of Marketing and Logistics, 19(1), 57-74. doi: doi:10.1108/13555850710720902.

8. Gupta, R. and Jain, K. (2015), 'Adoption behavior of rural India for mobile telephony: A multigroup study,' Telecommunications Policy, 39(8), 691-704.

9. Hall, M., de Jong, M. D. T. and Steehouder, M. F. (2004), 'Cultural differences and usability evaluation. Individualistic and collectivistic participants compared,' Technical communication, 51(4), 489-503.

10. Hammer, J. and Davidson, D. (2017), 'Cultural alignment and game-based learning. Educational Technology.' 57(2), pp. 31-35.

11. Hayes, A. F., Montoya, A. K. and Rockwood, N. J. (2017),'The analysis of mechanisms and their contingencies: 
PROCESS versus structural equation modeling,' Australasian Marketing Journal (AMJ), 25(1), 76-81. https://doi.org/10.1016/j.ausmj.2017. $\underline{02.001}$

12. Hofstede, G. (1983b), 'Culture's Consequences: International Differences in Work-Related Values,' Administrative Science Quarterly, $28(4), 625-629$.

13. Hofstede, G. (1991),'Cultures and Organizations: Software of the Mind: Intercultural Cooperation and its Importance for Survival,' McGraw-Hill International. ISBN: 0-07-707474-2.

14. Hofstede, G., Hofstede, G.J., 2005. 'Cultures and Organizations. Software of the Mind (2nd edt.),'. McGraw-Hill, New York (2005).

15. Hofstede, G. and Hofstede, J. (2010), 'Culture and Organizations-software of Minds,' McGraw- Hill international London.

16. Hofstede, G. (2011). Dimensionalizing Cultures: The Hofstede Model in Context Dimensionalizing Cultures: The Hofstede Model in Context, 2, 126.

17. Kasali, F. A., Awodele, O., Kuyoro, S., Akinsanya, A. and Eze, M. (2017), 'A conceptual design and evaluation framework for mobile persuasive health technologies (Usability approach).' Research Journal of Mathematics and Computer Science, 1 (4), 1- 16.

18. Kim, J. H. and Lee, K. P. (2005), 'Cultural difference and mobile phone interface design: icon recognition according to level of abstraction,' Paper presented at the Proceedings of the 7th international conference on Human computer interaction with mobile devices \&amp; services, Salzburg, Austria.

19. Kim, Y., Briley, D. A. and Ocepek (2015), 'M. G. Differential innovation of smartphone and application use by sociodemographics and personality,' Computers in Human Behavior, 44, 141-147.

20. Kamppuri, Minna \& Bednarik, Roman \& Tukiainen, Markku. (2006), 'The expanding focus of HCI: Case culture,' 189.

405-408.

$10.1145 / 1182475.1182523$.

21. Li, H., Rau, P.-L. P. and Hohmann, A. (2011), 'The Impact of Cultural Differences on Instant Messaging Communication in China and Germany,' In P. L. P. Rau (Ed.), Internationalization, Design and Global Development: 4th International Conference, IDGD 2011, Held as part of HCI International 2011, Orlando, FL, USA, July 9-14, 2011. Proceedings (pp. 75-84). Berlin, Heidelberg: Springer Berlin Heidelberg.

22. Li, J. (2016), 'Cultural Differences in the Use of Instant Messaging Applications: Cross-Cultural Case Study of China and the Netherlands,' University of Twente, pp. 36.

23. Oinas-kukkonen, H. and Harjumaa, M. (2009), 'Persuasive Systems Design: Key Issues, Process Model, and System Features', 24(1).

24. Parreño, J. M., Sanz-Blas, S., Ruiz-Mafé, C. and Aldás-Manzano, J. (2013), 'Key factors of teenagers' mobile advertising acceptance.' Industrial Management \& Data Systems, 113(5), 732-749.

http://doi.org/10.1108/02635571311 324179

25. Sánchez-Moya, A. and Cruz-Moya, 0. (2015). 'Hey there! I am using 
WhatsApp: A Preliminary Study of Recurrent Discursive Realisations in a Corpus of WhatsApp Statuses,' Procedia - Social and Behavioral Sciences, 212, 52-60. doi: http://dx.doi.org/10.1016/j.sbspro.20 15.11.298

26. Sawyer, R. (2011), 'The impact of new social media on intercultural adaptation,' University of Rohode Island DigitalCommons@URI.

27. Statista (2018), 'Number of mobile messages sent through WhatsApp as of 4th quarter 2017,' [online]. Available at:

https://www.statista.com/statistics/2 58743/daily-mobile-message-volumeof-whatsapp-messenger/ [Accessed 5 January, 2019].

28. Statista (2019), 'Most popular global mobile messenger apps as of October 2019,' Available online at: https://www.statista.com/statistics/2 58749/most-popular-global-mobilemessenger-apps/ [Accessed 5 December, 2019].
29. Steenkamp, J.-B. E. M. and Geyskens, I. (2006), 'How Country Characteristics Affect the Perceived Value of Web Sites,' Journal of Marketing, 70(3), pp. 136-150. doi: 10.1509/jmkg.70.3.136.

30. Sutikno, T., Handayani, L., Stiawan, D., Riyadi, M. and Subroto, I. (2016), 'WhatsApp, Viber and Telegram which is Best for Instant Messaging?' International Journal of Electrical and Computer Engineering (IJECE), 6(3), 909-914. doi: 0.11591/ijece. v6i3.10271

31. Turner, A. G. (2003), 'Sampling strategies. Handbook on designing of household sample surveys,' Geneva: United Nations Statistics Division.

32. Trompenaars, F. and Hampden-Turner, C. (1998), 'Riding the waves of culture,' New York: McGraw-Hill.

33. Zhou, L. (2005), 'An Empirical Investigation of Deception Behavior in Instant Messaging,' IEEE Transactions on Professional Communication, 48(2), 147-160. doi: 10.1109/ТPC.2005.849652. 